\title{
A COMPREENSÃO E A CONSCIÊNCIA TEXTUAL NO GÊNERO CRÔNICA: UMA PROPOSTA DE ENSINO PARA ALUNOS DO $9^{\circ}$ ANO DO ENSINO FUNDAMENTAL
}

\section{THE COMPREHENSION AND THE TEXTUAL AWARENESS IN CHRONIC GENDER: A TEACHING PROPOSAL FOR 9TH STUDENTS OF ELEMENTARY SCHOOL}

\author{
Patricia de Andrade Neves* \\ Caroline Bernardes Borges** \\ Vera Wannmacher Pereira***
}

\begin{abstract}
Resumo: Este artigo tem como objetivo propor atividades para desenvolvimento da compreensão leitora e da consciência textual no que se refere à coerência - manutenção e progressão temática -, sugeridas a alunos do $9^{\circ}$ ano do Ensino Fundamental. Além disso, também é objetivo do estudo analisar as atividades à luz das teorias que as embasam, de modo a contribuir com uma ferramenta para professores de Língua Portuguesa na formação leitora de seus alunos. Para tanto, primeiramente são apresentados os fundamentos teóricos do artigo - compreensão leitora (GOODMAN, 1976; KINTSCH, 1998; COLOMER \& CAMPS, 2002); tipo textual narrativo e gênero crônica (ADAM, 2011; CÂNDIDO, 1992); e consciência textual e coerência (GOMBERT, 1992; CHAROLLES, 1978). Logo após, são apresentadas as atividades propostas e suas respectivas análises.
\end{abstract}

Palavras-chave: Leitura. Narração. Ensino.

Abstract: This article aims to propose reading activities focusing on the development of reading comprehension and textual awareness regarding coherence - maintenance and thematic progression - , suggested to 9 th students of elementary school. Furthermore, it is also the objective of the study to analyze the activities in the light of the theories that underlie them, in order to contribute as a tool for Portuguese language teachers in their students reading education. Therefore, first the theoretical foundations of the article are presented - reading comprehension (GOODMAN, 1976; KINTSCH,

\footnotetext{
* Graduação em Letras Faculdade Porto-Alegrense (2013), Mestre em Linguística pela Pontifícia Universidade Católica do Rio Grande do sul - PUCRS (2017). Professora de Língua Inglesa no Colégio Israelita de Porto Alegre. Doutoranda pela Pontifícia Universidade Católica do Rio Grande do sul - PUCRS, na área da Psicolinguística, bolsista CNPq, e pesquisadora no Núcleo de Pesquisa em Cognição, Cultura, Linguagens e Interfaces: ciência, arte e tecnologia - NUCCLIN. E-mail:

** Doutoranda em Linguística pelo Programa de Pós-Graduação em Letras da Escola de Humanidades da PUCRS (Bolsista integral CNPq). Mestre em Linguística pelo PPGL/PUCRS (2018) Graduada em Letras (Licenciatura em Língua Portuguesa e respectivas Literaturas) pela Faculdade de Letras da PUCRS (2015). Membro dos grupos de pesquisa "Estudos Cognitivos e Culturais das Linguagens" (CNPq) e "Aquisição, aprendizado e processamento cognitivo da linguagem: instrumentos, procedimentos e tecnologias" (CNPq), que estão inseridos no Núcleo de Pesquisa em Cognição, Cultura, Linguagens e Interfaces: Ciência, Arte e Tecnologia, da PUCRS.

*** Bolsista de Produtividade DT do CNPq. Mestrado e doutorado em Letras (concentração em Linguística Aplicada) e pós-doutorado em Psicolinguística. Na Escola de Humanidades: Letras da PUCRS, é docente titular e permanente do PPGL. Desenvolve atividades como professora, pesquisadora e orientadora e coordena o Núcleo de Pesquisa em Cognição, Cultura, Linguagens e Interfaces: ciência, arte e tecnologia - NUCCLIN.
} 
1998; COLOMER \& CAMPS, 2002); narrative textual type and chronicle genre (ADAM, 2011; CÂNDIDO, 1992); and textual awareness and coherence (GOMBERT, 1992; CHAROLLES, 1978). Right after, the proposed activities and their respective analyzes are presented.

Keywords: Reading. Narrative. Teaching.

\section{Introdução}

A leitura, como forma de inserção na sociedade e no mercado de trabalho, possibilita que os sujeitos sintam-se atuantes no meio em que vivem, com condições mais adequadas de vida, do que decorre a importância da elaboração de materiais que auxiliem nesse processo, desenvolvendo a compreensão leitora de alunos da educação básica.

Tendo em vista esse cenário, o objetivo, neste artigo, é apresentar uma proposta de atividades que visam ao desenvolvimento da compreensão leitora e da consciência textual com foco na coerência - mais especificamente na manutenção e na progressão temática, direcionadas a alunos do $9^{\circ}$ ano do Ensino Fundamental.

Com a expectativa de instrumentalizar professores de Língua Portuguesa, de modo que possam contribuir para o desenvolvimento de habilidades metacognitivas, as atividades apresentadas são analisadas de acordo com as teorias que as fundamentam. Além de terem acesso às atividades, como recurso para uso em sala de aula, os professores poderão conhecer as bases de elaboração dessas atividades e, assim, produzirem outras nesse âmbito ou com enfoque em outros aspectos linguísticos.

Nesse sentido, o artigo está estruturado da forma descrita a seguir. Inicialmente, expõem-se tópicos referentes aos pressupostos teóricos que fundamentam o estudo: 1) leitura e compreensão leitora (GOODMAN, 1976; KINTSCH, 1998; COLOMER \& CAMPS, 2002); 2) tipo textual narrativo e gênero crônica (ADAM, 2011; CÂNDIDO, 1992); e 3) consciência textual e coerência (GOMBERT, 1992; CHAROLLES, 1978). Em seguida, são apresentados os encaminhamentos para o ensino - as atividades propostas e suas respectivas análises.

Espera-se que o estudo possa contribuir para o desenvolvimento da compreensão leitora e da consciência textual dos alunos, principalmente no que se refere à coerência textual de crônicas narrativas, de modo a alcançarem bons resultados em leitura e, consequentemente, em escrita.

\section{Leitura e compreensão leitora}

A evolução das diferentes culturas ao longo da História exigiu que o cérebro dos seres humanos se adaptasse às mudanças ocorridas através dos anos. Dentre tais evoluções, estão a leitura e a escrita, que fizeram com que nosso cérebro sofresse transformações. Para ler e escrever, o ser humano precisa de instrução, necessita aprender, diferentemente da fala e da escuta, que são desenvolvidas naturalmente a partir da exposição a um ambiente em que as pessoas se comuniquem por meio de determinada língua.

Além disso, há a evolução que ocorre desde que o ser humano nasce, cresce e começa a aprender a ler. A prática da leitura modifica a anatomia do cérebro à medida que o ser humano vai aprendendo a realizar tal atividade. A parte posterior do corpo caloso, que conecta as regiões parietais dos dois hemisférios cerebrais, torna-se mais espessa. Com 
isso, o hemisfério esquerdo, principal responsável pela leitura, consegue comunicar-se com o hemisfério direito em algumas situações em que é exigido, transformando a leitura em uma atividade interativa entre as áreas cerebrais (DEHAENE, 2012).

Quanto ao processamento da palavra escrita, há duas vias - a fonológica e a lexical (SCLIAR-CABRAL, 2008). Alguns pesquisadores defendem que a via fonológica é acessada somente na fase inicial da leitura, quando o indivíduo ainda está aprendendo a decodificar. Todavia, prevalece a concepção de que as duas vias são acessadas de forma simultânea durante a leitura, porém, como um leitor proficiente faz a passagem pela via fonológica de forma rápida e automática, parece que esse processo não foi realizado. Com isso, nosso léxico mental possibilita que as palavras sejam lidas como um todo e não apenas suas letras em sequência de forma segmentada.

A expansão do nosso córtex pré-frontal possibilitou a invenção da escrita, pois aumentou nossas capacidades mentais e, consequentemente, nossa memória suplementar, permitindo que desenvolvêssemos a habilidade de ler. Scliar-Cabral (2008) considera que a prática da leitura é possível por alguns aspectos cerebrais específicos: a plasticidade cerebral, que garante a reciclagem para novas aprendizagens; a especialização e a dominância de diferentes áreas do hemisfério esquerdo para o desenvolvimento da linguagem verbal; a interconexão entre diversas áreas cerebrais; e o processamento cerebral.

De acordo com Lent (2002), a decodificação é uma etapa fundamental para a leitura, porém, decodificar não é compreender. As sacadas oculares - quando os olhos se fixam em uma determinada parte do texto - fazem parte do processo de decodificação. Em cada sacada, os olhos podem reconhecer uma ou duas palavras. Assim, o sistema visual identifica os grafemas, as sílabas, os prefixos, os sufixos e os radicais. O autor (2002) explica o processo da leitura dividindo-o em ciclos. Conforme essa concepção, a leitura possui quatro ciclos, que ocorrem à medida que é realizada, um precedendo o outro até que o processo chegue ao fim. São eles: o ciclo ótico, o ciclo perceptual, o ciclo gramatical e o ciclo de sentido. Todos contribuem e encaminham para a compreensão, sendo no último que ela se completa.

Como já salientado, a leitura ocorre de forma interativa entre os hemisférios cerebrais. Newman et al. (2004) afirmam que a compreensão leitora ocorre, portanto, cooperativamente em ambos hemisférios. O esquerdo envolve principalmente o processamento lexical/semântico e sintático, enquanto o direito envolve a integração das informações textuais com o conhecimento de mundo, contribuindo para a realização das inferências e a compreensão da linguagem figurada.

Goodman (1976) define a leitura como um jogo psicolinguístico de adivinhação/predição. Há uma construção e uma reconstrução de diversos significados no ato de ler, na adaptação e na acomodação de uma nova informação ao significado que está sendo formado. Goodman (1991) afirma que o leitor constrói os sentidos textuais por meio de transações com o texto durante a leitura. Assim, a leitura é vista como uma escrita receptiva na visão transacional, ou seja, é por meio de transações com o texto e de forma indireta através do escritor com o texto que o significado é construído. Três perspectivas diferentes são levadas em conta nas transações linguísticas referentes à leitura: 1) o processo pelo qual o escritor produz o texto; 2) as características do texto; 3) o processo pelo qual o leitor constrói o significado. 
Kato (2007) classifica o processamento da leitura em dois tipos: o processamento top-down, que é não linear, descendente, dedutivo, ou seja, vai da macroestrutura do texto para a microestrutura, da função para a forma; e o processamento bottom-up, modelo linear, ascendente e indutivo, ocorre das menores unidades linguísticas para as maiores. Sendo assim, o processamento top-down é aquele realizado pelos leitores mais fluentes e velozes, que apreendem facilmente as ideias principais de um texto, fazendo uso de adivinhações com base em seus conhecimentos prévios. Já o processamento bottom-up está relacionado à leitura minuciosa, centrada na ortografia e em outros dados fornecidos pelo texto, sendo utilizado comumente pelos leitores mais vagarosos e menos fluentes na leitura. Estes leitores podem apresentar dificuldades para resumir as ideias do texto. O leitor maduro e proficiente realiza os dois processos de forma complementar e interativa, controlando seu uso de procedimentos e estratégias de leitura de forma consciente.

Em relação às estratégias de leitura, Kato (2007) as categoriza em cognitivas e metacognitivas. As estratégias cognitivas são aquelas realizadas de forma inconsciente e automática por parte do leitor, enquanto as estratégias metacognitivas referem-se aos comportamentos conscientes do leitor ao longo da leitura. Segundo a autora, as estratégias metacognitivas, se ensinadas explicitamente, contribuem para o desenvolvimento da compreensão leitora, na medida em que há o esclarecimento dos propósitos de leitura, a identificação das ideias principais e secundárias dos textos, a distribuição da atenção (resultando em maior ou menor concentração por parte do leitor), o monitoramento das atividades (para constatação da efetivação da compreensão leitora e do alcance dos objetivos de leitura), a tomada de decisões corretivas quando detectadas falhas na compreensão; e prevenção contra distrações e truncamentos.

Colomer \& Camps (2002) enfatizam que qualquer prática de leitura sempre terá a compreensão leitora como finalidade natural. Segundo os autores, dois elementos principais condicionam a compreensão leitora: a intenção do leitor e os conhecimentos prévios. Por meio do propósito da leitura há a determinação da forma como será abordada a mensagem pelo leitor e o nível de compreensão exigido em uma leitura específica. Por sua vez, a capacidade de ativar um grande número de esquemas de conhecimentos (tanto linguísticos quanto sobre o mundo) também propicia a prefiguração do desenvolvimento do texto de forma mais previsível e facilita a compreensão leitora.

Por fim, apresenta-se o Modelo de Construção-Integração de Kintsch (1998) como uma das bases deste estudo. O modelo considera a compreensão um processo inferencial por natureza, baseado em duas dimensões essenciais: o texto base, que é a representação mental construída a partir de informações apresentadas no texto; e o modelo situacional, que é a representação mental constituída com base no conhecimento prévio do leitor, na qual as lacunas do texto são preenchidas por meio do estabelecimento de inferências.

Tendo sido apresentados os pressupostos referentes à leitura e à compreensão, passemos, na seção a seguir, ao tópico referente ao tipo textual narrativo e ao gênero crônica, características dos textos utilizados nas atividades propostas.

\section{0 tipo textual narrativo e o gênero crônica}

Por vezes, as noções de tipo textual e gênero textual são confundidas e tratadas de forma equivocada no ensino. De acordo com Marcuschi (2003), tipo textual é a expressão 
que designa uma série de constructos teóricos caracterizados por determinadas propriedades linguísticas, formando uma sequência de enunciados dominantes e um conjunto de elementos lexicais e relações lógicas. Podem ser, por exemplo, a narração, a argumentação, a exposição, a descrição e a injunção.

Já a expressão gênero textual refere-se aos textos que estão inseridos em nosso cotidiano de forma materializada, classificados de acordo com as características que possuem em comum, envolvendo também os gêneros literários (TRAVAGLIA, 2002; MARCUSCHI, 2003). Tais características estão relacionadas ao conteúdo, a propriedades funcionais, estilo, composição, etc. São exemplos de gêneros: crônica, fábula, mito, notícia, receita, artigo de opinião, bula de remédio, etc. Destaca-se que os textos não verbais também compõem os gêneros textuais.

Nas atividades de leitura propostas no presente estudo, o tipo textual narrativo é focalizado. Conforme Cardoso (2000), a narrativa é caracterizada pelo relato de acontecimentos das realizações e atividades humanas, em que o espaço e as personagens são descritos e estão inseridos em um enredo. Polkinghorne (1988) a define como uma estrutura de significação que organiza os acontecimentos e as ações humanas de maneira geral, isto é, atribui significado às ações e aos acontecimentos, já que esses só podem ser descritos e analisados por meio da narrativa. Além disso, organiza tais acontecimentos em uma sequência de fatos coerente, atribuindo temporalidade à estrutura.

A criança interage com a narrativa desde antes do nascimento - tem os primeiros contatos com a linguagem oral ainda na barriga da mãe, ouvindo tudo que dizem a sua volta. Depois que nasce, esse contato com as narrativas ocorre por meio da contação de histórias e da reprodução do seu próprio discurso narrativo oral (CARDOSO, 2000). Howard (1991) afirma que todos os pensamentos humanos condizem com o tipo textual narrativo, visto que toda sua estruturação ocorre nesse sentido. Bruner (1986) define a narrativa como forma de expressão dos acontecimentos humanos com significado.

Para Travaglia (2002), o tipo textual narrativo possui como conteúdo temático os acontecimentos ou fatos que estão organizados em episódios. Ocorre a indicação e o detalhamento (geralmente, por meio de descrição de lugar, de tempo, dos participantes/personagens), acrescidos do acontecimento (ações, fatos ou fenômenos que ocorrem).

De forma didática, Adam (2011) propõe um modelo ideal de narrativa. Segundo o autor, as narrativas possuem uma estrutura hierárquica com certo número de sequências, e, para que um texto tenha um alto grau de narrativização, o enredo deve ser constituído por cinco proposições essenciais. São elas: Pn1 - a situação inicial, que antecede o processo; Pn2 - o nó, parte inicial do processo; Pn3 - a avaliação, que corresponde ao percurso do processo; Pn4 - o desenlace, referente ao final do processo; e Pn5 - a situação final, que ocorre após o processo. Na ausência de qualquer uma das cinco proposições citadas, o texto é considerado com baixo grau de narrativização. Adam (2011) apresenta, ainda, duas proposições que são opcionais na narrativa: Pn0 - a abertura do texto, podendo ser um resumo ou prefácio, e $\operatorname{Pn} \Omega$ - o encerramento do texto.

A definição de narrativa proposta por Van Dijk (2008) pode servir de complemento à definição de Adam. Ao apresentar as características dos textos narrativos, declara que toda a narrativa possui três macrocategorias fundamentais - a situação, a compilação e a resolução - e duas que são opcionais - a avaliação e a moral. 
Adam (2011) declara que, por meio das cinco proposições essenciais, uma série de elementos são apresentados ao leitor e constituem a estrutura da narrativa, como, por exemplo, narrador, enredo, espaço, tempo e personagens. Além disso, deve haver uma transformação, ou seja, uma mudança do estado inicial para o estado final, ocorrendo o clímax, que resultará na conclusão do texto. Sobre isso, declara:

Vimos que o reagrupamento de proposições narrativas em tríades imbricadas constitui grupos de funções. São estes grupos de proposições organizadas em ciclos que formam as sequências narrativas. Para que um grupo de proposições narrativas forme uma sequência é preciso não somente que um mesmo ator as unifique atravessando-as, mas também que haja uma transformação (ADAM, 2011, p.54).

O autor define uma sequência narrativa como uma unidade textual complexa, constituída por um número limitado de enunciados. Assim, envolve uma estrutura organizada em uma rede de relações hierárquicas, sendo uma entidade autônoma e de forma relativa, determinada por sua organização interna.

Dessa forma, acredita-se que as sequências narrativas dominantes são importantes na constituição das atividades para desenvolvimento da compreensão leitora com enfoque na coerência textual, pois todo o texto narrativo necessita da ordem cronológica e lógica para ser coerente, abordando uma sequência de fatos, a temporalidade, etc., elementos necessários para o estabelecimento da coerência, como exposto mais adiante.

Entendidos os elementos e definições do tipo textual selecionado, passemos aos fundamentos do gênero textual que compõe a base das atividades: a crônica. A crônica, gênero que possui sequências narrativas dominantes, surgiu no jornalismo brasileiro com os folhetins, nos quais os jornais reservavam um espaço específico para registrar os acontecimentos atuais da época. Sendo assim, conforme Melo (1985), a crônica como conhecemos hoje é um gênero tipicamente brasileiro.

Em sua etimologia, a palavra crônica está relacionada à palavra grega chronos, que significa "tempo" (TUZINO, 2010). De acordo com a autora, o conceito atual da palavra crônica, de sentido literário, passou a ser utilizado somente no século XIX, definida como uma espécie de narrativa sobre acontecimentos históricos atuais à época, presentes nos jornais impressos.

Neiva (2005) ressalta que, desde que a crônica ganhou espaço nos jornais impressos, principalmente com os textos de Machado de Assis, o fator tempo passou a não ser mais determinante em alguns casos. Segundo a autora (2005, p. 4), "O aspecto cronológico cedeu caminho às inúmeras possibilidades de significados da crônica, a sua abrangência temática e linguística", embora algumas crônicas necessitem exclusivamente da contextualização temporal para serem compreendidas.

A crônica passou por algumas modificações através do tempo, passando a ser mais curta e concisa, de modo que o cronista pudesse estabelecer um elo com o leitor, devido à proximidade construída (LETRIA, 2000). Melo (1985) classifica as crônicas em: crônicadiálogo, em que o cronista e o interlocutor trocam informações e expõem pontos de vista; a crônica-narrativa, que possui uma estrutura de ficção, similar à do conto; a crônica exposição poética, em que o cronista retrata de forma livre um fato ou uma personagem; e a crônica biografia lírica, em que o cronista narra poeticamente a vida de alguém. Nota-se, assim, que a crônica é um gênero híbrido em que há a intercalação entre a objetividade do 
texto jornalístico e a subjetividade do texto literário, constituindo um gênero com propriedades intertextuais e intergêneros (FIX, 1997).

Segundo Cândido (1992), a crônica trata de assuntos cotidianos e contemporâneos, com uma linguagem mais despojada e coloquial. Como na contemporaneidade os acontecimentos ocorrem rapidamente e logo são sobrepostos por novos acontecimentos, o cronista, ao estabelecer um ritmo ágil para acompanhá-los, utiliza uma sintaxe mais solta, garantindo uma coloquialidade que auxilia o leitor no estabelecimento dos cenários, dos fatos e das pessoas (SÁ, 2002). O coloquialismo é um aspecto que atrai o leitor, com a função de divertimento, informação e ilustração, muitas vezes lançando mão do humor para construção de seus enredos.

Entendidos os pressupostos teóricos do tipo textual e do gênero selecionados para compor as atividades de leitura propostas, é apresentado, a seguir, o tópico correspondente à consciência textual e à coerência.

\section{Consciência textual e coerência}

Pelo viés psicolinguístico, a consciência textual faz parte da consciência linguística, que é mais abrangente. Caracterizada pelo monitoramento e pela observação dos aspectos linguísticos de forma consciente, a consciência linguística pode estar relacionada aos diferentes planos linguísticos que subjazem à língua.

A consciência fonológica, por exemplo, focaliza a manipulação dos fonemas da língua e é importante facilitador na aprendizagem da leitura. A consciência morfológica, por sua vez, focaliza o morfema. A consciência lexical focaliza a palavra e, segundo Tunner et al. (1984), possui três fases que emergem em momentos distintos: a consciência da palavra como uma unidade de linguagem, a consciência da palavra como um rótulo arbitrário e a compreensão do termo palavra pelo viés metalinguístico. A consciência sintática focaliza as frases, sendo voltada à habilidade de reflexão sobre a estrutura gramatical interna das sentenças e mensurada, geralmente, por meio de tarefas de julgamentos de aceitabilidade, de ambiguidades, de sinônimos, de discriminação, entre outras. Já a consciência pragmática focaliza a relação entre o sistema da língua e o contexto construído por ele, no qual está inserido, estabelecendo o sentido total dos textos.

Gombert (1992) inovou os estudos acerca da consciência linguística acrescentando a consciência textual, que focaliza o monitoramento do texto como um todo. $\mathrm{O}$ autor declara que trata-se de operações metatextuais que ocorrem por meio do controle deliberado da compreensão e da produção textual. Assim, o texto é o objeto de análise e suas propriedades são verificadas por meio de monitoramento intencional.

A consciência textual constitui o centro do presente estudo, visto que as atividades elaboradas pretendem desenvolver essa habilidade, focalizando aspectos relacionados à coerência dos textos. Gombert (1992) ressalta que a consciência textual exige que o indivíduo volte a sua atenção para o texto de forma consciente, considerando propriedades como: a estrutura - traços que definem o gênero textual; a coerência, ou seja, as relações estabelecidas pelo conteúdo; a coesão - relações entre os elementos gramaticais e lexicais e sua contribuição para a amarração do texto; e a consciência procedimental, que está relacionada aos procedimentos que o leitor utiliza para compreender o texto.

Além do monitoramento da leitura, da compreensão e da manipulação de partes do texto, a escrita e revisão também fazem parte da consciência textual. A atividade 
metatextual tem importante papel no monitoramento da escrita, pois estratégias são utilizadas para escrever e revisar textos. Desse modo, ao desenvolver os comportamentos metalinguísticos, em que o indivíduo julga os elementos linguísticos de forma consciente e explicita verbalmente os critérios utilizados, a consciência textual também é desenvolvida.

Pereira \& Scliar-Cabral (2012) declaram que a consciência textual envolve a relação existente entre os aspectos internos do texto e o contexto, englobando a coerência, a coesão e a superestrutura. Karmiloff-Smith (1985) e Fayol (1985) destacam que, segundo a perspectiva metatextual, a coerência é focalizada; a coesão, por sua vez, é monitorada por meio do enfoque no processamento dos marcadores superficiais que se destinam a assegurar a unidade textual. O termo coerência envolve, então, variáveis semânticas, enquanto o termo coesão está relacionado a variáveis morfossintáticas.

Gombert (1992) destaca que as pesquisas com intuito de avaliar a consciência textual mensuram, por exemplo, a habilidade na distinção de um texto e de um não texto, na detecção de sentenças não relacionadas ao tema indicado no título e na distinção das ideias principais e secundárias em um texto. As atividades para desenvolvimento da consciência linguística, como salienta o autor, constituem um meio de controlar o processamento textual em relação aos aspectos formais, além de servir como referência nas representações de informações não necessariamente linguísticas que permeiam o texto.

Como salientado, uma das propriedades verificadas por meio de monitoramento intencional dos textos é a coerência. Essa é a propriedade focalizada nas atividades propostas por este estudo, para desenvolvimento da consciência textual, sendo detalhada a seguir em suas características.

A coerência textual é uma das propriedades responsáveis pela textualidade, ou seja, pelas relações de sentido entre as palavras, frases e parágrafos que compõem o texto, bem como entre o texto e seu entorno (GOMBERT, 1992). Assim, o texto somente será coerente se for composto por ideias conectadas. A monitoração da coerência, então, está relacionada à detecção de contradições no nível conceitual, isto é, à percepção de contradições a partir de novas informações ou informações que o sujeito já possui de forma explícita ou implícita no texto. Do mesmo modo, a coerência também é comprometida quando há contradições entre as informações textuais e as já existentes como conhecimentos prévios do leitor (coerência extratextual), sendo o processo inferencial responsável por possibilitar que o leitor interprete e atribua coerência aos textos.

Portanto, é sempre necessário estabelecer a relação entre o que é fornecido pela mensagem do texto e os dados extralinguísticos, para que o sentido seja construído ou problemas sejam detectados. Dessa forma, a coerência não é um aspecto explícito e pontual do texto, ela é global e faz parte da macroestrutura textual, estabelecida pelo todo, com suporte da boa formação textual.

De acordo com Charolles (1978), a coerência é estabelecida por meio de quatro metarregras, definidas da seguinte forma: 1) metarregra de manutenção temática: prevê, para que haja coerência, a necessidade da ocorrência de repetições, que podem ser estabelecidas por diferentes recursos linguísticos; 2) metarregra de progressão temática: mesmo com a manutenção do tema, a progressão deste se faz necessária, evitando o truncamento do desenvolvimento do texto, ou seja, evitando que se torne circular; 3) metarregra de não contradição interna: a introdução de uma nova informação ao desenvolvimento que seja contraditória à informação anterior compromete a coerência, podendo estar no nível do tema ou no nível linguístico; e 4) metarregra de relação com o 
mundo: os fatos, ações e estados descritos no texto devem estar relacionados com o mundo - no caso de textos não ficcionais, deve haver relação de verdade, e no caso de texto ficcionais, deve haver relação de verossimilhança.

O pesquisador afirma que, para assegurar a manutenção temática de um texto, diferentes recursos linguísticos são utilizados, como citado na metarregra 1, acima. Alguns deles são: as pronominalizações, que referem-se à utilização de pronomes (fenômenos anafóricos e catafóricos) como forma de retomar elementos anteriormente citados; as definitivações e referenciações também permitem retomadas de um substantivo de uma frase para outra e de uma sequência para outra; as substituições lexicais, que ocorrem com o uso de dêiticos, por exemplo; as recuperações pressuposicionais e as retomadas de inferência, que se referem às retomadas relacionadas aos conteúdos semânticos não expostos explicitamente, precisando ser reconstruídos a fim de tornarem-se explícitos. O autor (1978, p. 58) enfatiza que "Esses mecanismos de repetição favorecem o desenvolvimento temático contínuo do enunciado, permitem um jogo, submetido a regras, de retomadas a partir das quais se encontra estabelecido 'um fio textual condutor' [...]".

Koch (2002) considera que a progressão textual é construída por meio de dois movimentos: a prospecção, ou seja, o avanço do texto, e retroação, que retoma informações já utilizadas. As atividades elaboradas para o presente estudo utilizam textos com sequências narrativas dominantes, que possuem uma progressão temática caracterizada pela ordem temporal. Desse modo, aprender explicitamente as partes da narrativa possibilita a identificação e a construção de um texto coerente.

Expostos os fundamentos teóricos que embasaram a elaboração das atividades e o estudo como um todo, na próxima seção são apresentados os encaminhamentos para o ensino, considertando a metodologia empregada na elaboração dessas atividades e na realização de suas respectivas análises.

\section{Encaminhamentos para o ensino}

As atividades propostas contemplam quatro crônicas humorísticas de sequências narrativas dominantes. O gênero textual crônica se caracteriza por tratar de assuntos cotidianos com uma linguagem com tendência ao coloquial. A crônica é considerada um gênero menor por se aproximar dos leitores, por meio de uma linguagem que os ajuda a estabelecer os cenários, os fatos e as pessoas, muitas vezes utilizando o humor. Nesse gênero, o coloquialismo é um traço que atrai o leitor, com a função de divertimento, informação e ilustração, por meio de uma linguagem direcionada aos leitores do jornal (CÂNDIDO, 1992). Assim, a escolha por esse gênero textual se deu pelo fato de a crônica, ao possuir todas as características mencionadas anteriormente, ser potencialmente atrativa e interativa para os alunos do $9^{\circ}$ ano do Ensino Fundamental.

Nas atividades, as crônicas são organizadas a partir das proposições narrativas de Adam (2011), ou seja, os textos são pertencentes ao tipo textual narrativo. Os textos narrativos são adequados para o trabalho com esses alunos, pois fazem parte do cotidiano dos estudantes em geral. Os seres humanos pensam, fantasiam, compreendem e fazem escolhas mentalmente tendo como base uma estrutura narrativa, visto que tais textos contemplam a construção de significado tanto a experiências passadas como a experiências futuras (SARBIN, 1986). Além disso, considerando os conceitos de Adam (2011), a narrativa possui uma determinada estrutura envolvendo elementos como narrador, enredo, 
espaço, tempo e personagens. Desse modo, o trabalho com as sequências narrativas dominantes podem auxiliar na compreensão leitora, pois todo o texto narrativo necessita da ordem cronológica e lógica para ser coerente, além disso, deve haver uma mudança do estado inicial para o final, juntamente com o clímax da narrativa, resultando na conclusão do texto.

Portanto, as atividades trabalham com a análise e a percepção da compreensão leitora e da consciência textual no que se refere à coerência. Gombert (1992) postula que o trabalho com a consciência textual faz com que o indivíduo volte a sua atenção para o texto de maneira consciente. A coerência, por exemplo, é um dos aspectos que pode ser trabalhado na consciência textual. Dessa forma, as duas propostas a seguir visam à coerência textual por meio de duas metarregras propostas por Charolles (1978): a progressão e a manutenção temática, que se caracterizam respectivamente pela ordenação temporal e pela repetição da ideia central do texto.

\subsection{Proposta I}

Neste item é disponibiizada a primeira proposta, sendo primeiramente analisados os textos (três crônicas) e posteriormente apresentadas as atividades. A crônica "Papagaio Congelado" de Ricardo Azevedo, a primeira, está organizada da seguinte forma, com base em Adam (2011):

\begin{tabular}{|l|l|}
\hline (Pn1) situação inicial & Um dia, um sujeito ganhou de presente um papagaio. \\
\hline (Pn2) nó & $\begin{array}{l}\text { O bicho era uma praga. Não demorou muito, logo se espalhou } \\
\text { pela casa Atendia telefone. Gritava e falava sozinho nas horas } \\
\text { mais inesperadas. Dava palpite nas conversas dos outros. } \\
\text { Discutia futebol. Fumava charuto. Pedia café, tomava, cuspia, } \\
\text { arregalava os olhos, esparramava semente de girassol e cocô } \\
\text { por todo lado, gargalhava e ainda gritava para o dono de casa: } \\
\text { "Ô seu doutor, vê se não torra faz favor!". }\end{array}$ \\
\hline $\begin{array}{l}\text { (Pn3) reação ou } \\
\text { avaliação }\end{array}$ & $\begin{array}{l}\text { Uma noite, a família recebeu uma visita para jantar. O } \\
\text { papagaio não gostou da cara do visitante e berrou: "Vai } \\
\text { embora, ratazana!" e começou a falar cada palavrão cabeludo } \\
\text { que dava medo.Depois que a visita foi embora, o dono da casa } \\
\text { foi até o poleiro. Estava furioso: } \\
\text { - Seu mal-educado, sem-vergonha de uma figa! Estou cheio! } \\
\text { Agora você vai ver o que é bom pra tosse.Agarrou o papagaio } \\
\text { pelo cangote e atirou dentro da geladeira: - Vai passar a } \\
\text { noite aí de castigo! Depois, fechou a porta e foi dormir. }\end{array}$ \\
\hline (Pn4) desenlace & $\begin{array}{l}\text { No dia seguinte, saiu atrasado para o trabalho e esqueceu o } \\
\text { coitado preso dentro da geladeira. Só foi lembrar do bicho à } \\
\text { noite, quando voltou para casa. Foi correndo abrir a } \\
\text { geladeira.O papagaio saiu trêmulo e cabisbaixo, com cara } \\
\text { arrependida, cheio de pó gelado na cabeça.Ficou de }\end{array}$ \\
\hline
\end{tabular}




\begin{tabular}{|l|l|}
\hline & $\begin{array}{l}\text { joelhos.Botou as duas asas na cabeça.Rezou.Disse pelo amor } \\
\text { de Deus. } \\
\text { Reconheceu que estava errado.Pediu perdão.Disse que nunca } \\
\text { mais ia fazer aquilo.Jurou que nunca mais ia fazer coisa } \\
\text { errada, que nunca mais ia atender telefone e interromper } \\
\text { conversa, nem xingar nenhuma visita.Jurou que nunca mais ia } \\
\text { dizer palavrão nem "vai embora, ratazana". }\end{array}$ \\
\hline (Pn5) situação final & $\begin{array}{l}\text { Depois, examinando o homem com os olhos arregalados, } \\
\text { espiou dentro da geladeira e perguntou: - Queria saber só uma } \\
\text { coisa: o que é que aquele franguinho pelado, deitado ali no } \\
\text { prato, fez? }\end{array}$ \\
\hline
\end{tabular}

A crônica analisada tem a divisão dos fatos, conforme as proposições narrativas de Adam (2011): na situação inicial (Pn1), um homem ganha um papagaio de presente; no nó (Pn2), o papagaio tem péssimo comportamento na nova casa; na reação (Pn3), o homem coloca o papagaio dentro da geladeira de castigo; no desenlace (Pn4), o homem sai para trabalhar e esquece o papagaio o dia inteiro na geladeira e depois o resgata; e, na situação final (Pn5), o papagaio assustado pergunta sobre o que o frango que estava na geladeira tinha feito de errado.

A crônica "Fuga" de Fernando Sabino, a segunda, está organizada como segue, com base em Adam (2011):

\section{(Pn1) situação inicial}

(Pn2) nó
Mal o pai colocou o papel na máquina, o menino começou a empurrar uma cadeira pela sala, fazendo um barulho infernal. Pára com esse barulho, meu filho - falou, sem se voltar. Com três anos já sabia reagir como homem ao impacto das grandes injustiças paternas: não estava fazendo barulho, estava só empurrando uma cadeira.- Pois então pare de empurrar a cadeira. - Eu vou embora - foi a resposta.

Distraído, o pai não reparou que ele juntava ação às palavras, no ato de juntar do chão suas coisinhas, enrolando-as num pedaço de pano. Era a sua bagagem: um caminhão de plástico com apenas três rodas, um resto de biscoito, uma chave (onde diabo meteram a chave da despensa - a mãe mais tarde irá dizer), metade de uma tesourinha enferrujada, sua única arma para a grande aventura, um botão amarrado num barbante. A calma que baixou então na sala era vagamente inquietante. De repente, o pai olhou ao redor e não viu o menino.Deu com a porta da rua aberta, correu até o portão: - Viu um menino saindo desta casa? gritou para o operário que descansava diante da obra do outro lado da rua, sentado no meio-fio. - Saiu agora mesmo com uma trouxinha - informou ele. 


\begin{tabular}{|l|l|}
\hline $\begin{array}{l}\text { (Pn3) reação ou } \\
\text { avaliação }\end{array}$ & $\begin{array}{l}\text { Correu até à esquina e teve tempo de vê-lo ao longe, caminhando } \\
\text { cabisbaixo ao longo do muro. A trouxa, arrastada no chão, iam } \\
\text { deixando pelo caminho alguns de seus pertences: o botão, o } \\
\text { pedaço de biscoito e - saíra de casa prevenido - uma moeda de 1 } \\
\text { cruzeiro. Chamou-o, mas ele apertou o passinho, abriu a correr } \\
\text { em direção à Avenida, como disposto a atirar-se diante do ônibus } \\
\text { que surgia à distância. - Meu filho, cuidado! O ônibus deu uma } \\
\text { freada brusca, uma guinada para a esquerda, os pneus cantaram } \\
\text { no asfalto. O menino, assustado, arrepiou carreira. O pai } \\
\text { precipitou-se e o arrebanhou com o braço como a um } \\
\text { animalzinho: }\end{array}$ \\
\hline (Pn4) desenlace & $\begin{array}{l}\text { - Que susto você me passou, meu filho - e apertava-o contra o } \\
\text { peito, comovido. - Deixa eu descer, papai. Você está me } \\
\text { machucando. Irresoluto, o pai pensava agora se não seria o caso } \\
\text { de lhe dar umas palmadas: - Machucando, é? Fazer uma coisa } \\
\text { dessas com seu pai. - Me larga. Eu quero ir embora }\end{array}$ \\
\hline (Pn5) situação final & $\begin{array}{l}\text { Trouxe-o para casa e o largou novamente na sala - tendo antes o } \\
\text { cuidado de fechar a porta da rua e retirar a chave, como ele fizera } \\
\text { com a da despensa. - Fique aí quietinho, está ouvindo? Papai } \\
\text { está trabalhando.- Fico, mas vou empurrar esta cadeira. E o } \\
\text { barulho recomeçou. }\end{array}$ \\
\hline
\end{tabular}

A crônica examinada tem a divisão dos fatos, conforme as proposições narrativas de Adam (2011): na situação inicial (Pn1), o pai estava tentando trabalhar enquanto o menino estava fazendo barulho empurrando a cadeira; no nó (Pn2), o menino junta suas coisas e sai para a rua por seu pai ter o repreendido; na reação (Pn3), o pai sai atrás do filho e o encontra; no desenlace (Pn4), o pai agarra o menino para levá-lo até em casa; na situação final (Pn5), o menino, agora em casa novamente, volta a fazer barulho empurrando a cadeira.

A crônica "Garoto linha-dura" de Stanislaw Ponte Preta, a terceira, está organizada da seguinte forma, com base em Adam (2011):

\begin{tabular}{|l|l|}
\hline (Pn1) situação inicial & $\begin{array}{l}\text { Deu-se que Pedrinho estava jogando bola no jardim e, ao } \\
\text { emendar a bola de bico por cima do travessão, a dita foi de contra } \\
\text { uma vidraça e despedaçou tudo. Pedrinho botou a bola debaixo } \\
\text { do braço e sumiu até a hora do jantar, com medo de ser } \\
\text { espinafrado pelo pai. }\end{array}$ \\
\hline (Pn2) nó & $\begin{array}{l}\text { Quando o pai chegou, perguntou à mulher quem quebrara o vidro } \\
\text { e a mulher disse que foi Pedrinho, mas que o menino estava com } \\
\text { medo de ser castigado, razão pela qual ela temia que a criança } \\
\text { não confessasse o seu crime. O pai chamou Pedrinho e } \\
\text { perguntou: - Quem quebrou o vidro, meu filho? }\end{array}$ \\
\hline
\end{tabular}




\begin{tabular}{|l|l|}
\hline (Pn3) reação ou & $\begin{array}{l}\text { Pedrinho balançou a cabeça e respondeu que não tinha a mínima } \\
\text { ideia. O pai achou que o menino estava ainda sob o impacto do } \\
\text { nervosismo e resolveu deixar para depois. Na hora em que o } \\
\text { jantar ia para a mesa, o pai tentou de novo: - Pedrinho, quem foi } \\
\text { que quebrou a vidraça, meu filho? - E, ante a negativa reiterada } \\
\text { do filho, apelou: - Meu filhinho, pode dizer quem foi que eu } \\
\text { prometo não castigar você. Diante disso, Pedrinho, com a maior } \\
\text { cara-de-pau, pigarreou e lascou: - Quem quebrou foi o garoto do } \\
\text { vizinho. - Você tem certeza? - Juro. }\end{array}$ \\
\hline (Pn4) desenlace & $\begin{array}{l}\text { Aí o pai se queimou e disse que, acabado o jantar, os dois iriam } \\
\text { ao vizinho esclarecer tudo. Pedrinho concordou que era a melhor } \\
\text { solução e jantou sem dar a menor mostra de remorso. Apenas - } \\
\text { quando o pai fez ameaça - Pedrinho pensou um pouquinho e } \\
\text { depois concordou. Terminado o jantar o pai pegou o filho pela } \\
\text { mão e - já chateadíssimo - rumou para a casa do vizinho. Foi aí } \\
\text { que Pedrinho provou que tinha ideias revolucionárias. Virou-se } \\
\text { para o pai e aconselhou: }\end{array}$ \\
\hline (Pn5) situação final & $\begin{array}{l}\text { Papai, esse menino do vizinho é um subversivo desgraçado. } \\
\text { Não pergunte nada a ele não. Quando ele vier atender a porta, o } \\
\text { senhor vai logo tacando a mão nele. }\end{array}$ \\
\hline
\end{tabular}

A crônica analisada tem a divisão dos fatos, conforme as proposições narrativas de Adam (2011): na situação inicial (Pn1), Pedrinho estava jogando bola e quebrou a vidraça; no nó (Pn2), o pai de Pedrinho chega em casa e lhe pergunta quem tinha quebrado a vidraça; na reação (Pn3), Pedrinho afirma que foi o filho do vizinho quem quebrou a vidraça; no desenlace (Pn4), o pai de Pedrinho decide levá-lo até a casa do vizinho para esclarecer as coisas; e, por fim, na situação final (Pn5), Pedrinho aconselha o pai a não conversar com o filho do vizinho, mas já chegar batendo nele.

Tendo como objeto de estudo essas três crônicas, são expostas a seguir atividades que podem ser realizadas com alunos de final do Ensino Fundamental, nesta Proposta I: Os alunos (acomodados conforme a demanda da sala de aula) recebem as três crônicas embaralhadas e fora da ordem, com os textos divididos em trechos segundo as proposições explanadas na teoria. Dessa forma, os textos divididos nas proposições narrativas de Adam (2011) também auxiliam na percepção sobre a construção de um texto narrativo coerente. É solicitado aos alunos que separem os três textos embaralhados, ou seja, trabalhem a manutenção temática de cada crônica, que, segundo Charolles (1978), é uma das responsáveis pela coerência textual, pois o texto também precisa se manter em um mesmo eixo temático para ser coerente. Ademais, a atividade solicita que os alunos coloquem os trechos dos textos na ordem narrativa, ou seja, trabalhem também a progressão temática, que, segundo Charolles (1978), também é uma das responsáveis pela coerência textual, pois mesmo com o tema textual sendo mantido o texto deve progredir. Assim, o equilíbrio entre as novas informações que são introduzidas no texto e a temática textual é proporcionado por essas duas regras. Além disso, o processamento utilizado pelos alunos durante a execução da atividade é percebido através de um protocolo verbal oral no formato de um podcast (áudio gravado). Os alunos devem relatar como pensaram para executar essa 
atividade e em seguida enviar o áudio para o e-mail do professor. Logo, por meio do desenvolvimento dos comportamentos metalinguísticos (o indivíduo julga de forma consciente e explicita verbalmente os critérios utilizados), a consciência textual no que se refere à coerência também é desenvolvida. Para finalizar, o professor confronta as respostas dos alunos por meio do compartilhamento dos áudios com o grande grupo e promove uma discussão e uma reflexão sobre a execução da atividade. É provável que o trabalho com a coerência textual de maneira lúdica e interativa possa ser instigante para os alunos. Desse modo, ao se trabalhar a manutenção temática, a progressão temática e o protocolo verbal oral, a consciência textual também é beneficiada.

\subsection{Proposta II}

Neste item é disponibilizada a segunda proposta, sendo primeiramente analisado o texto (uma crônica) e posteriormente são apresentadas as atividades. A crônica "O Revólver do Senador”, de Fernando Sabino, está organizada da seguinte forma (ADAM, 2011):

\begin{tabular}{|c|c|}
\hline Pn1 (situação inicial/orientação) & $\begin{array}{l}\text { O Senador ainda estava na cama, lendo } \\
\text { calmamente os jornais, e eram dez horas da } \\
\text { manhã. Súbito ouve a voz do netinho de } \\
\text { quatro anos de idade por detrás da folha } \\
\text { aberta, bem junto de sua cabeça: }\end{array}$ \\
\hline Pn2 (nó/desencadeador) & $\begin{array}{l}\text { - Vovô, eu vou te matar. Abaixou o jornal e } \\
\text { viu, aterrorizado, que o menino empunhava } \\
\text { com as duas mãos o revólver apanhado na } \\
\text { gaveta da cabeceira. Sempre tivera a arma } \\
\text { ali ao seu alcance, para qualquer } \\
\text { eventualidade, carregada e com uma bala na } \\
\text { agulha. Nunca essa eventualidade se dera } \\
\text { na longa sequência de riscos e tropeços que } \\
\text { a política lhe proporcionara. No entanto, ali } \\
\text { estava, agora, apanhado de surpresa, sob a } \\
\text { mira de um revólver. O menino começou a } \\
\text { rir de sua cara de espanto. - Eu vou te } \\
\text { matar - repetiu, dedinho já no gatilho. }\end{array}$ \\
\hline Pn3 (Re-ação ou avaliação) & $\begin{array}{l}\text { O menor gesto precipitado e a arma } \\
\text { dispararia. Pensou em estender o braço e ao } \\
\text { menos afastar o cano de sua testa, que já } \\
\text { começava a porejar suor. Mas temeu o } \\
\text { susto da criança, o dedo se contraindo no } \\
\text { gatilho... Tentou falar e de seus lábios } \\
\text { saíram apenas sons roufenhos e mal } \\
\text { articulados. - Não me mata não - gaguejou, } \\
\text { afinal: - você é tão bonzinho... - Pum! } \\
\text { Pum! - e o demônio do menino sempre a } \\
\text { rir, só fez dar um passo para trás; que o }\end{array}$ \\
\hline
\end{tabular}




\begin{tabular}{|c|c|}
\hline & $\begin{array}{l}\text { colocou fora de seu alcance. Agora estava } \\
\text { perdido. - Cuidado, tem bala... - deixou } \\
\text { escapar, e a voz de novo lhe faltou. Toda } \\
\text { uma vida que terminava ali, estupidamente } \\
\text { nas mãos de uma criança - de que } \\
\text { adiantara? Tudo aflição de espírito e } \\
\text { esforço vão. Se alguém entrasse no quarto } \\
\text { de repente, a mãe, a avó do menino... Que é } \\
\text { isso, menino! Você mata seu avô! Com o } \\
\text { susto... Senti o pijama já empapado de suor. } \\
\text { Era preciso fazer alguma coisa, terminar } \\
\text { logo com aquela agonia. Estendeu } \\
\text { mansamente o braço trêmulo: - Me dá isso } \\
\text { aqui...- Mãos ao alto! - berrou o menino, } \\
\text { ameaçador, dando passo para trás, e as } \\
\text { mãos pequeninas se firmaram ainda mais } \\
\text { no cabo da arma. O Senador não teve outra } \\
\text { coisa a fazer senão obedecer. } \\
\text { E assim se compôs o quadro grotesco: o } \\
\text { velho com os braços erguidos, o guri a } \\
\text { dominá-lo com o revólver. }\end{array}$ \\
\hline Pn4 (Desenlace/Resolução) & $\begin{array}{l}\text { De repente, porém, o telefone tocou. - } \\
\text { Atende aí - pediu o senador, num sopro. } \\
\text { Estava salvo: o menino tomou do fone, } \\
\text { descobrindo brinquedo novo, e abaixou o } \\
\text { revólver. O Senador aproveitou a trégua } \\
\text { para apoderar-se da arma. Então pôs-se a } \\
\text { tremer, descontrolado, enquanto retirava as } \\
\text { balas com os dedos aflitos. O menino } \\
\text { começou a chorar:- Me dá! Me dá! }\end{array}$ \\
\hline Pn5 (Situação Final) & $\begin{array}{l}\text { A mulher do senador vinha entrando: }-\mathrm{O} \\
\text { que foi que você fez com ele? Está com } \\
\text { uma cara esquisita... Que aconteceu? - } \\
\text { Acabo de nascer de novo - explicou } \\
\text { simplesmente. }\end{array}$ \\
\hline
\end{tabular}

A crônica está dividida conforme as proposições narrativas de Adam (2011). Essas sequências possuem uma progressão temática caracterizada pela ordenação temporal; por esse motivo, ter conhecimento das partes da narrativa auxilia na construção de um texto coerente no aspecto da progressão temática, embasando a atividade linguisticamente. Os alunos (acomodados conforme a demanda da sala de aula) recebem a crônica faltando uma parte (uma das proposições em que o texto está dividido). Uns recebem o texto faltando a Pn1 (situação inicial/orientação), outros a Pn2 (nó), outros a Pn3 (reação ou avaliação), outros a Pn4 (desenlace) e outros a Pn5 (situação final). Em seguida, os alunos são solicitados a criar (de maneira escrita) uma nova parte coerente para a proposição da 
crônica que está faltando e assim perceber o eixo central temático do texto e a progressão temática textual.

Segundo Gombert (1992), a coerência textual é uma das responsáveis pela textualidade, ou seja, a habilidade de o indivíduo refletir sobre as relações de sentido entre as frases que formam um texto. Logo, um texto coerente é aquele que possui ideias conectadas; a coerência não aparece de forma explícita no texto, é global e faz parte da macroestrutura textual (sentido do texto unificado e mantido, além da boa formação textual). Assim, por meio da elaboração de uma novo trecho para a crônica, a coerência textual, no que se refere à manutenção e à progressão temática, é trabalhada. A progressão temática proporciona o equilíbrio entre as novas informações que são introduzidas e a temática textual anterior; visto que a continuidade temática (manutenção temática) deve ser mantida mesmo que novos tópicos sejam abordados na produção textual. Segundo os linguistas da Escola Funcionalista de Praga, para auxiliar na compreensão da progressão temática, o tema é a informação que já está contida no texto (ou seja, as proposições narrativas existentes na crônica) e o rema é a informação nova (ou seja, o novo trecho a ser criado pelos alunos), sendo tais características parte do avanço/progressão textual. Em seguida, os alunos são solicitados a fazer uma contação da crônica na íntegra (incluindo a parte que foi criada, no formato de um podcast, ou seja, áudio gravado), e a enviar essa produção para o $e$-mail do professor. Para finalizar, o professor faz a contação da crônica no seu formato original e compartilha com os demais as novas versões do texto por meio dos áudios enviados, promovendo assim uma reflexão e uma discussão sobre os processos desenvolvidos.

\section{Considerações finais}

Neste artigo estão apresentadas duas propostas de atividades de leitura com foco no desenvolvimento da compreensão leitora e da consciência textual no que se refere à coerência - manutenção e progressão temática -, sugeridas a alunos do $9^{\circ}$ ano do Ensino Fundamental. Estão apoiadas teoricamente em estudos sobre a consciência metalinguística, em Gombert (1992); sobre a coerência, em Charolles (1978); sobre as sequências narrativas dominantes, em Adam (2011); sobre tipo textual e gênero textual, em Marcuschi (2003); e sobre a crônica, em Cândido (1992).

As atividades têm como objeto de estudo o gênero textual crônica e o tipo textual narrativo. O gênero crônica, segundo Fargoni (1993, p. 238), contém "índices de oralidade, explicitados tanto em elementos verbais como em não verbais que envolvem a conversação por ela simulada". Portanto, esse gênero textual pode ter uma boa aceitação por parte dos alunos dessa faixa etária, já que possui uma linguagem despojada, coloquial e se utiliza do humor. O texto narrativo, para Gonçalves \& Henriques (2000), é uma espécie de representação de uma realidade cognitiva essencial, todavia com a experiência do indivíduo como elemento central. Ademais, o trabalho com as proposições narrativas de Adam (2011) também auxilia na percepção dos alunos sobre como se dá a construção de um texto narrativo coerente. Desse modo, a escolha pelo tipo textual narrativo nas atividades sugeridas a alunos do $9^{\circ}$ ano do Ensino Fundamental é pertinente.

A compreensão leitora e a consciência textual são os enfoques linguísticos abordados nas atividades. A leitura, para Goodman (1976), é considerada um jogo psicolinguístico de adivinhação/predição que relaciona de maneira articulada a linguagem e 
o pensamento. Portanto, "A busca de significado é a característica mais importante do processo de leitura", visto que é por meio de uma construção e uma reconstrução de diversos significados no ato de ler que há a adaptação e a acomodação de uma nova informação ao significado que está sendo formado. Já a consciência textual é responsável por voltar a atenção do leitor para o texto de forma consciente (GOMBERT, 1992). Dentre os aspectos da consciência textual, a coerência é central, pois através dela as ideias do texto são conectadas, sendo ela uma das responsáveis pela textualidade.

Segundo Karmiloff-Smith (1985) e Fayol (1985b), a coerência versa sobre a vinculação das ideias no nível de representação cedida pelo texto. Essa afirmação é respaldada por Charolles (1978), nos seus estudos sobre a coerência textual, já que o autor lança mão de metarregras que constituem um texto coerente. Dentre as metarregras preconizadas por Charolles, o enfoque do artigo está na metarregra de manutenção temática (a coerência também se dá por meio da manutenção do tema) e de progressão temática (mesmo com o tema devendo ser mantido, a progressão deste se faz necessária, evitando que o texto seja repetitivo) objetivando, assim, um recorte teórico e um direcionamento para as atividades propostas.

Através dos tópicos linguísticos elucidados anteriormente, tendo com ponto de partida o cenário educacional nacional, buscou-se elaborar e analisar atividades de compreensão leitora e consciência textual que possam ser utilizadas em sala de aula, com alunos do $9^{\circ}$ ano do Ensino Fundamental e servirem de base para a elaboração de novas atividades similares. Portanto, espera-se que o estudo possa possibilitar ao professor uma ferramenta que amenize as falhas de leitura e escrita apresentadas pelos alunos e oportunize o desenvolvimento da compreensão leitora e da consciência textual, principalmente no que se refere à coerência textual.

\section{Referências}

ADAM, J-M. A Línguística Textual. São Paulo: Cortez, 2011.

BRUNNER, J.S. Actual minds, possible worlds. Cambridge: Harvard University Press, 1986.

CÂNDIDO, A. A Crônica:o gênero, sua fixação e suas transformações no Brasil.

Campinas: Editora da UNICAMP; Rio de Janeiro: Fundação Casa de Rui Barbosa, 1992, $551 \mathrm{p}$.

CARDOSO, C. J. Da oralidade à escrita: a produção do texto narrativo no contexto escolar. Cuiabá: UFMG; INEP; MEC, 2000.

CHAROLLES, M. Introduction aux problèmes de la cohérence des textes. Paris: Langue Française, 1978.

COLOMER, T. e CAMPS, A. Ensinar a ler, ensinar a compreender. Porto Alegre: Artmed, 2002. 
DEHAENE, S. Os neurônios da leitura - como a ciência explica a nossa capacidade de ler. Porto Alegre: Penso, 2012.

FARGONI, A. M. S. L. A manifestação da oralidade na escrita. 1993.

f. Dissetração (Mestrado em) - Universidade Estadual "Júlio de Mesquita Filho", Araraquara.

FAYOL, Michel. Le récit et sa construction. Une approche de psychologie cognitive. Neuchâtel: Delachaux \& Niestlé, 1985b.

FIX, Ursula. Tipologische Intertextualität - ein "postmodernes" Stilmittel? In: Antos, G.; Tietz, H. (hgg). Die zukunft der textlinguistik. Traditionen Transformationen Trends. Tübingen: Max niemeyer verlagg, 1997. p. 96-108

GOMBERT, J-E. Metalinguistic development. Hertfordshire: Harverster Wheatsheaf, 1992.

GONÇALVES, M.; HENRIQUES, M. Terapia narrativa da ansiedade. Coimbra: Quarteto, 2000 .

GOODMAN, K. S. Um jogo psicolinguístico de adivinhação. In: SINGER, Harry; RUDDELL, Robert B. Theoretical models and processes of reading. 2. ed. Newark: International Reading Association, 1976.

GOODMAN, K. S. Unidade na leitura - um modelo psicolinguístico transacional. Letras de Hoje, Porto Alegre, v. 26, n. 4, p. 9-43, dez. 1991.

KARMILOFF-SMITH, Annette. Language and cognitive processes from a development perspective. In: Language and Cognitive Processes, 1, p. 61-85, 1985.

KATO, M. A. O aprendizado da leitura. São Paulo: Martins Fontes, 2007.

HOWARD, G. A narrative aproach to thinking, cross-cultural psychology and psychotherapy. American Psychologist, v. 46, n. 3, primavera 1991.

KINTSCH, W. Comprehension: a paradigm for cognition. Cambridge: Cambridge University Press, 1998.

KOCH, I. V. Desvendando os segredos do texto. São Paulo: Cortez, 2002.

LENT, R. Cem bilhões de neurônios: conceitos fundamentais de neurociência. São Paulo: Atheneu: FAPERJ, 2002.

LETRIA, J. Pequeno breviário jornalístico. 2. ed. Lisboa: Notícias Editorial, 2000. 
MARCUSCHI, Luiz Antônio. Gêneros textuais: definição e funcionalidade. In Gêneros textuais e ensino. Rio de Janeiro: Lucena, 2003, p. 20-36.

MELO, José Marques de. Aopinião no jornalismo brasileiro. Petrópolis - RJ:

Vozes, 1985.

NEIVA, Érica Michelline Cavalcante.A crônica no jornal impresso brasileiro, 2005.

Disponível em: <www.unirevista.unisinos.com.br>. Acesso em 10 mai. 2019

NEWMAN, S. D.; JUST, M. A.; MASON, R. Compreendendo o texto com o lado direito do

cérebro: o que os estudos de neuroimagem funcional têm a dizer. In: RODRIGUES, C.; TOMITCH, L. (Orgs.) Linguagem e cérebro humano: contribuições multidisciplinares. Porto

Alegre: Artmed, 2004.

PEREIRA, V. W.; SCLIAR-CABRAL, L. Compreensão de textos e consciência textual Caminhos para o ensino nos anos iniciais. Florianópolis: Insular, 2012.

POLKINGHORNE, D. P. Narrative psychology. New York: Suny Press, 1988.

SÁ, J. A crônica. São Paulo: Ática, 2002.

SARBIN, T. R. (Org.). Narrative psychology: the storied nature of conduct. New York: Praeger, 1986.

SCLIAR-CABRAL, L. Processamento bottom-up na leitura. Revista de Estudos Linguísticos Veredas: Psicolinguística. Juiz de Fora: UFJF, v. 12, n. 2, p. 24-33, 2008.

TRAVAGLIA, Luiz Carlos. Tipelementos e a construção de uma teoria tipológica geral de textos. São Paulo: Mimeo, 2002.

TUNMER, W.; PRATT, C.; HERRIMAN, M. (Orgs.). Metalinguistic awareness in children: theory, research and implications. Nova York: Springer-Verlag, 1984.

TUZINO, Yolanda Maria Muniz. Crônica: uma intersecção entre o jornalismo e a literatura. In: Biblioteca on-line de ciências da comunicação, 2010.

VAN DIJK, Teun Adrianus. Discurso e poder. São Paulo: Contexto, 2008.

Recebido em 08 de agosto de 2019

Aceito em 27 de novembro de 2019 